\title{
Controlling the Shape, Pore Size and Surface Area of Prepared Mesoporous Silica Particles by Altering the Molar Concentration of Tetramethoxysilane
}

\author{
Mohammed M. Algaradah \\ Department of Chemistry, King Khalid Military Academy, Riyadh, Kingdom of Saudi Arabia \\ Email: garadah1972@hotmail.com
}

How to cite this paper: Algaradah, M.M. (2021) Controlling the Shape, Pore Size and Surface Area of Prepared Mesoporous Silica Particles by Altering the Molar Concentration of Tetramethoxysilane. American Journal of Analytical Chemistry, 12, 446-457. https://doi.org/10.4236/ajac.2021.1211028

Received: October 25, 2021

Accepted: November 27, 2021

Published: November 30, 2021

Copyright $\odot 2021$ by author(s) and Scientific Research Publishing Inc. This work is licensed under the Creative Commons Attribution International License (CC BY 4.0).

http://creativecommons.org/licenses/by/4.0/

\begin{abstract}
In recent days, the applications of silica-based nanoparticles have gained much attention. The preparation of mesoporous silicas is usually achieved via the modified Stöber method, the reaction attained by the hydrolysis and condensation of silica precursors present within a medium containing template, solvent, deionized water (DI-W) and base. Therefore, the current study aimed to prepare and characterize mesoporous silicas by using tetramethoxysilane (TMOS) as silica precursor and ethylene glycol (Et-G) as solvent. The study was based on the template dodecyltrimethylammonium bromide ( $\left.\mathrm{C}_{12} \mathrm{TMABr}\right)$ and sodium hydroxide used as an alkaline agent. Mesoporous silicas were prepared in various batches based on TMOS molar concentration, ionized water, $\mathrm{NaOH}$, and other solvents. The characterization of mesoporous silicas was achieved based on their specific surface area, pore size distribution and morphology using different instruments: Brunauer, Emmett \& Teller (BET), scanning electron microscopy (SEM), Fourier-transform infrared spectroscopy (FT-IR), and thermalgravimetric analysis (TGA). The study revealed that shape, average particle sizes " 35 to $550 \mathrm{~nm}$ ", average pore radius " $1.62-4.5$ $\mathrm{nm}$ ” and surface area " $350-1204 \mathrm{~m}^{2} \cdot \mathrm{g}^{-1}$ " of obtained mesoporous silica particles were altered based on precursor concentration and other factors. Therefore, it is important to get the most suitable concentration of all chemicals in the preparation of mesoporous silicas to control the particle characteristics to use them upon their further applications. This is the baseline study that provides details regarding prepared silica particles with controlled characteristics, and more studies related to its applications are still in process.
\end{abstract}




\section{Keywords}

Nanoparticles, Mesoporous Silica, Stöber Method, Fourier-Transform

Infrared Spectroscopy (FT-IR), Dodecyltrimethylammonium Bromide

$\left(\mathrm{C}_{12} \mathrm{TMABr}\right)$

\section{Introduction}

The preparation of mesoporous silica was first achieved by Kresge's team in 1992 using surfactant as a template [1]. After surfactant removed from the mesostructure, mesoporous silicas with pores sizes in the range of 2 to $10 \mathrm{~nm}$ and hexagonal and cube arrays were obtained. Various studies were conducted to prepare mesoporous silicas with different pore sizes and surface areas. The preparation of mesoporous silica depends on three main steps: 1) synthesis, 2) drying, and 3) removing the surfactant. The synthesis of mesoporous silicas is the curial step where it is necessary to control all the properties of mesoporous silica [2].

It is therefore important to select the reaction components to prepare mesoporous silica with the desired characteristics. The drying step is usually carried out at a temperature not exceeding $45^{\circ} \mathrm{C}$ as it is important to remove water and solvent from the mesostructure slowly so that it does not collapse. The final step is the removal of the template by either burning or solvent extraction. The last two steps have limited effect in controlling pore size and surface area [3] [4].

A large number of researchers worked on preparing mesoporous [5] and macroporous silicas [6], but few of them were able to prepare it with an average particles size less than $500 \mathrm{~nm}$. Several factors can be taken into consideration to control the pore size, surface area, particle size, and morphology. These factors include type of surfactant and its chain length, solvent kind and quantity, $\mathrm{pH}$ of the reaction medium and stirring speed [7]. For instance, mesoporous silica batches were successfully prepared by Yano and Fukushima using alkyl trimethylammonium chloride with varieties alkyl lengths as a template and TMOS as a silica source. Methanol and deionized water are the most commonly used as a solvent and the medium for $\mathrm{pH}$ was altered to alkaline by adding $\mathrm{NaOH}$ [8]. Spherical particles with multiple sizes were obtained and the size of the particles is directly proportional to the length of the alkyl chain. Moreover, mesoporous silica with an average size " $136 \mathrm{~nm}$ " and surface area " $1006 \mathrm{~m}^{2} \cdot \mathrm{g}^{-1}$ " and mercapto chelator was attached to the surface of these particles for analytical applications [5].

Furthermore, various difficulties were faced by the researchers during the preparation of mesoporous silica and the major concerns are to control the shape of the particle and the size of pores with high surface area. Therefore, the current study was designed to control the shape, size of the pores, and surface area by altering the molar concentration of TMOS and other reaction contents during 
silica preparation process.

\section{Materials}

In the current study, the synthesis of mesoporous silica was achieved by using different materials: Tetramethoxysilane "98\%", $\mathrm{NaOH}$, Dodecyltrimethylammonium bromide "99\%", and Ethylene glycol and they were purchased from $\mathrm{Al}$ drich, UK, whereas, ethanol was used as grading reagents.

\section{Characterization of Prepared Particles}

The obtained mesoporous silica particles in this work were characterized using TGA, FT-IR, SEM and BET.

Thermal analysis of the particles was carried out using TGA under these conditions: Heat temperature " $30^{\circ} \mathrm{C}-800^{\circ} \mathrm{C}$ " at $2^{\circ} \mathrm{C} / \mathrm{min}$, under $\mathrm{N}_{2}$ and the weight of sample " $1-5 \mathrm{mg}$ ". Perkin-Elmer TGA 8000 was used.

FT-IR spectroscopy measurement was carried out for silica samples directly as a solid material before and after combustion.

SEM was utilized to evaluate the morphology of prepared particles and to measure the size of the particles based on the average size of 50 particles. Before the measurement take place, sample prepared by dispersing $10 \mathrm{mg}$ of silica particles in deionized water and drops placed onto glass plate. The glass surface was then coated using gold film and the measurement was carried out using focused ion-beam microscopy type FEI Helios Nanolab 600.

Surface area and pore size distribution was measured using Micromeritics ASAP 2020 apparatus.

\section{Preparation of Mesoporous Silicas}

The preparation of mesoporous silicas was achieved by transferring ethylene glycol "0 - $400 \mathrm{~mL}$ ", deionised water " 0 - $400 \mathrm{~mL}$ ", sodium hydroxide solution "0 - $9 \mathrm{~mL}, 1 \mathrm{M}$ ", and $\mathrm{C}_{12} \mathrm{TMABr}$ "0 - $3.36 \mathrm{~g}$ " into a conical flask "1000 mL". The mixture was stirred vigorously for $15 \mathrm{~min}$ at $20^{\circ} \mathrm{C}$. TMOS " $0.9-3.6 \mathrm{~mL}$ " was then slowly added and the reaction was left to proceed for $8 \mathrm{~h}$ under vigorous stirring (Table 1). The mixture was then aged overnight. The white solid was isolated by centrifugation " $10,000 \mathrm{rpm}$ " for $30 \mathrm{~min}$, rinsed with water five times and one additional time with ethanol, and then dried at $45^{\circ} \mathrm{C}$ for 3 days. The white powder was calcinated at $550^{\circ} \mathrm{C}$ for $12 \mathrm{~h}$, the temperature increased from room temperature to $550^{\circ} \mathrm{C}$ at $2^{\circ} \mathrm{C} / \mathrm{min}$.

\section{Results and Discussion}

\subsection{Effect of Tetramethoxysilane}

In the current study, TMOS was used as a silica precursor instead of tetraethoxysilane (TEOS) which commonly used to synthesis mesoporous silica particles. The hydrolysis process of TMOS faster than TEOS as the TMOS has a small leaving group leading to the fast formation of the particles [9]. The 
Table 1. The materials and quantities used to prepare different batches of mesoporous silicas.

\begin{tabular}{|c|c|c|c|c|c|}
\hline Experiment & $\begin{array}{l}\text { TMOS } \\
(\mathrm{mL})\end{array}$ & $\begin{array}{c}\mathrm{C}_{12} \mathrm{TMABr} \\
(\mathrm{g})\end{array}$ & $\begin{array}{l}\text { DI-W } \\
(\mathrm{mL})\end{array}$ & Et-G & $\begin{array}{c}\mathrm{NaOH} \\
(\mathrm{mL})\end{array}$ \\
\hline MG-1 & 1.8 & 1.68 & 310 & 90 & 3 \\
\hline MG-2 & 0.9 & 1.68 & 310 & 90 & 3 \\
\hline MG-3 & 3.6 & 1.68 & 310 & 90 & 3 \\
\hline MG-4 & 1.8 & 1.68 & 200 & 200 & 3 \\
\hline MG-5 & 1.8 & 1.68 & 90 & 310 & 3 \\
\hline MG-6 & 1.8 & 1.68 & 400 & 0 & 3 \\
\hline MG-7 & 1.8 & 1.68 & 0 & 400 & 3 \\
\hline MG-8 & 1.8 & 1.68 & 310 & 90 & 0 \\
\hline MG-9 & 1.8 & 1.68 & 310 & 90 & 6 \\
\hline MG-10 & 1.8 & 1.68 & 310 & 90 & 9 \\
\hline MG-11 & 1.8 & 0 & 310 & 90 & 3 \\
\hline MG-12 & 1.8 & 0.84 & 310 & 90 & 3 \\
\hline MG-13 & 1.8 & 3.36 & 310 & 90 & 3 \\
\hline
\end{tabular}

${ }^{*} \mathrm{~mL}=$ milliliters, $\mathrm{g}=$ grams, Et-G $=$ ethylene glycol.

$\mathrm{C}_{12} \mathrm{TMABr}$ was used as a template, due to its short chain length surfactant was expected to produce small size particles. The ethylene glycol was used as a solvent instead of ethanol or methanol which is responsible to enhance the viscosity of the reaction mixture followed by huge numbers of primary particles subsequently size of particles can be controlled [10]. The reaction mixture during synthesis of silica particles usual catalysis by adding $\mathrm{NH}_{4} \mathrm{OH}$, however, in the current study $\mathrm{NaOH}$ was used for the synthesis of short silicate rod-like micelles to form small particles [11]. Every component of the reaction mixture plays a key role in particles formation. Therefore, the quantity of the reaction recipe was altered to study the effect of each reagent on particles characteristics to get desirable particles.

In the current study, the mesoporous silica particles were prepared and categorized based on varied morphology, size, surface area and pore size distribution by altering the amount of silica precursor, solution and surfactant (Table 1) with keeping other factors such as temperature and stirring are constant. The reaction was initiated by adding different concentrations of silica precursor, the concentration is gradually increased in overall experimentation to observe the changes in prepared silicas. It was observed that variation in TMOS concentration affects the size and porosity of mesoporous silicas which was observed by scanning electron microscopy (Figure 1). The reaction was categorized in 13 batches from MG-1 to MG-13. The alteration in TMOS showed that perfect and homogenous spherical particles with a mean size of ca. $157 \pm 23 \mathrm{~nm}$ were obtained in MG-1 

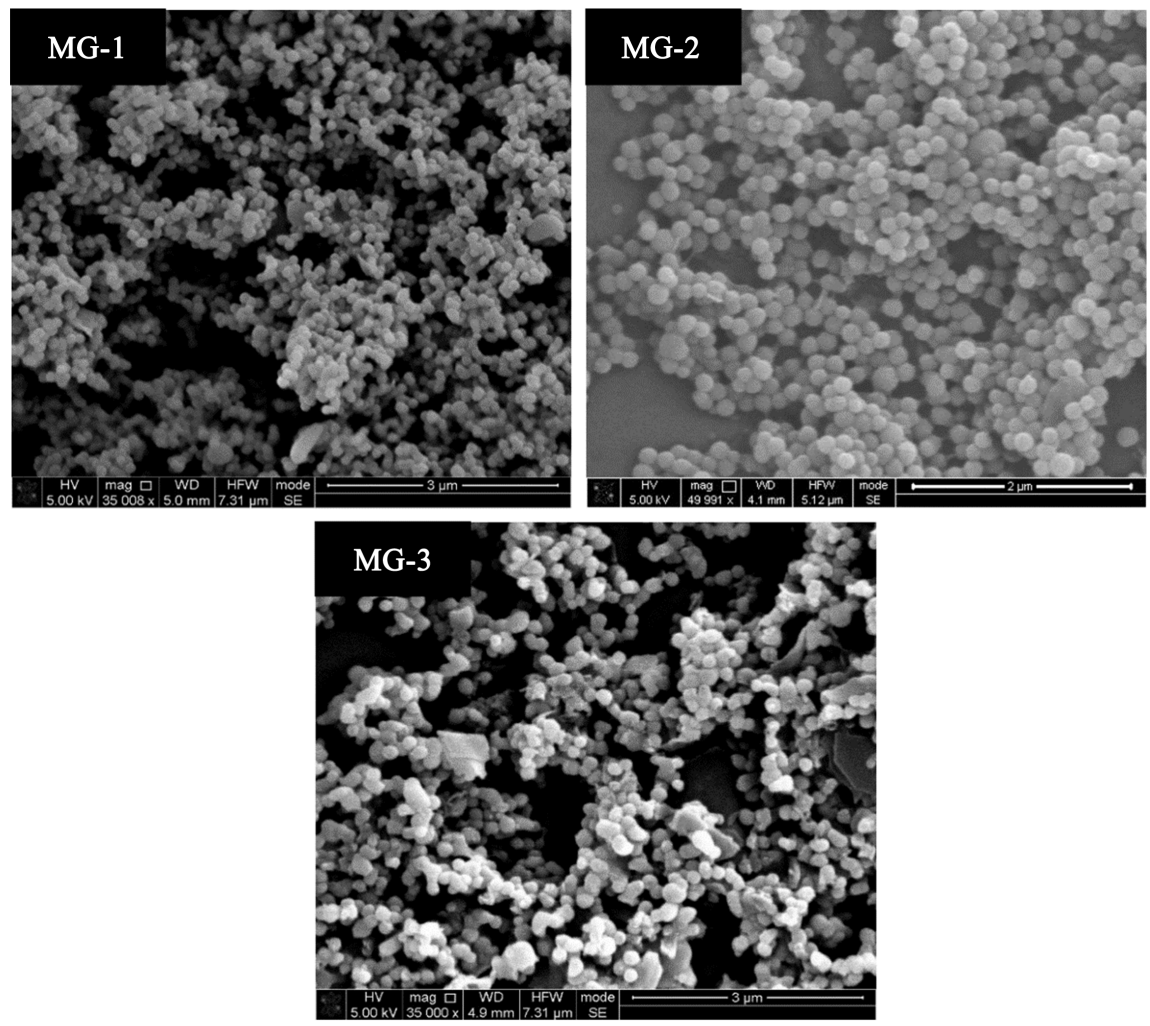

Figure 1. SEM Images of silica particles prepared by altering the quantity of TMOS (Batch MG-1, MG-2, and MG-3).

"TMOS, $1.8 \mathrm{~mL}$ ". It was observed that when the concentration of TMOS was $50 \%$ decreased it brings a remarkable change in the size and physical state of silicas. The shape of mesoporous silica particles was spherical with irregular shapes with a mean size of ca. "149 $\pm 20 \mathrm{~nm}$ " (Figure 1). Hence, there was not a big difference observed at a reduced concentration of TMOS. When the concentration of TMOS gradually increased $100 \%$ from the standard " $1.8 \mathrm{~mL}$ " in the reaction mixture, it was observed that spherical particles and some little amorphous one were obtained (Figure 1). The increased concentration of TMOS leads to huge numbers of small-seeded particles with limited precursors being available for subsequent particles growth. Therefore, the study also confirms that the size of particles at an increased concentration of TMOS was reduced to $120 \mathrm{~nm}$ (Table 1) [12] [13]. The particle dispersion for the batches MG-1 and MG-3 were sufficient whereas, reasonable for batch MG-2 due to the amorphous nature of particles.

\subsection{Effect of Volume Ratio of Solvent (DI-W: Et-G)}

To study the effect of solvents (DI-W and Et-G) on the size and morphology of the particles. The experiments were designed to make the sum of solvent to be 400 mL "Batch MG-1 and MG-4-7". In batch MG-1 DI-W "310 mL" and Et-G " $90 \mathrm{~mL}$ " were utilized during the whole experiment. The size and morphology of this batch showed that the morphology of prepared particles was affected by in- 
creasing the volume ratio of ethylene glycol (Figure 2). It was observed that the increased volume of ethylene glycol in the reaction mixture led to a decrease in the solubility of the surfactant and hindered the formation of micelle as it has been observed no spherical particles obtained in high concentration of ethylene glycol "Batch MG-5". Table 2 illustrates the size and some of the characteristics of prepared particles [14].

\subsection{Alkaline Reagent $(\mathrm{NaOH})$}

The effect of alkaline reagent $\mathrm{NaOH}$ on the formation of the particles was studied "Batch MG-1, MG-8 - 10". The concentration of $\mathrm{NaOH}$ was modified from "0 - $9 \mathrm{~mL}$ ". A glass material was obtained when the experiment run without the base which confirms the need for the reaction medium to be either in the basic or acidic condition (Table 2). Increasing the $\mathrm{pH}$ value of the reaction medium lead to a bigger particle with irregular shapes and sizes (Figure 3) [15]. However, cluster of amorphous materials produced at high concentration of $\mathrm{NaOH}$ "Batch MG-10".

\subsection{Template Dodecyltrimethylammonium Bromide}

The size of particles depends on the alkyl length chain of the surfactant. It has been reported that the average particle size increased when the alkyl-chain length of the surfactant was increased [16]. In the literature, there is not much data available regarding the effect of surfactant quantity on the morphology and
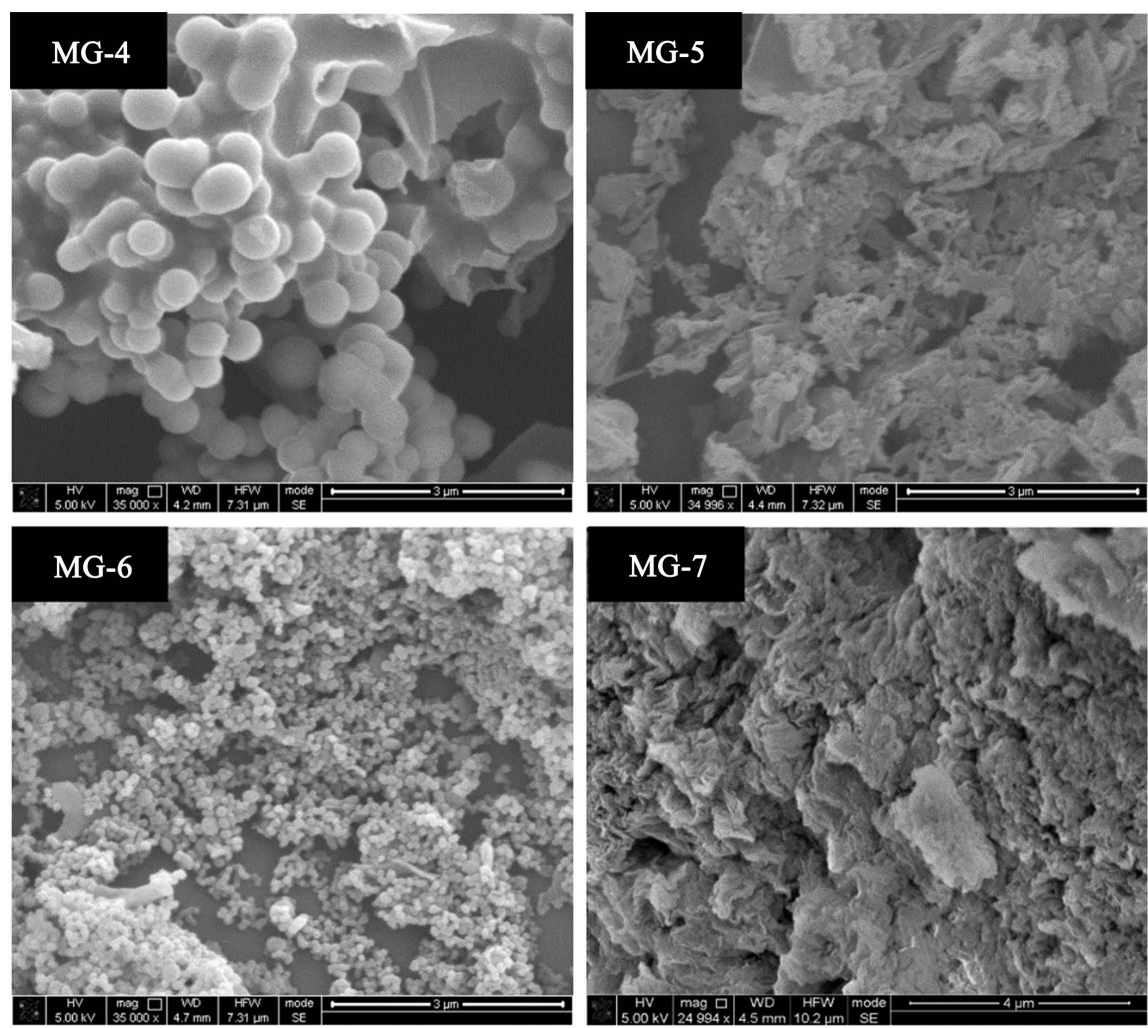

Figure 2. SEM Images of silica particles (Batch MG-4-7). 
Table 2. Some characteristics for different batches of mesoporous silicas.

\begin{tabular}{|c|c|c|c|c|}
\hline Batch & $\begin{array}{l}\text { Main Change on the } \\
\text { Reaction content }\end{array}$ & $\begin{array}{c}\text { Particles } \\
\text { size } \pm \text { SD }(n m)\end{array}$ & $\begin{array}{c}\text { Dispersion } \\
\text { of the particles }\end{array}$ & Characteristics of the particles \\
\hline MG-1 & TMOS $=1.8 \mathrm{~mL}$ & $157 \pm 23$ & Good dispersion & Spherical particles \\
\hline MG-2 & $\mathrm{TMOS}=0.9 \mathrm{~mL}$ & $149 \pm 20$ & $\begin{array}{l}\text { Reasonable } \\
\text { dispersion }\end{array}$ & $\begin{array}{l}\text { Irregular spherical particles, } \\
\text { some amorphous particles }\end{array}$ \\
\hline MG-3 & $\mathrm{TMOS}=3.6 \mathrm{~mL}$ & $120 \pm 11$ & Good dispersion & Spherical particles \\
\hline MG-4 & DI-W: Et-G $=(200: 200) \mathrm{mL}$ & $531 \pm 143$ & Poor dispersion & $\begin{array}{l}\text { Irregular particles shape, } \\
\text { some amorphous particles }\end{array}$ \\
\hline MG-5 & DI-W: Et-G = (90:310) mL & $\begin{array}{c}\text { No spherical } \\
\text { particles formed }\end{array}$ & Poor dispersion & Sheet of amorphous materials \\
\hline MG-6 & DI-W: Et-G = (400:0) & $100 \pm 24$ & Reasonable dispersion & $\begin{array}{c}\text { Spherical particles, } \\
\text { some amorphous sheet }\end{array}$ \\
\hline MG-7 & DI-W: Et-G $=(0: 400) \mathrm{mL}$ & $157 \pm 23$ & Poor dispersion & Cluster of amorphous materials \\
\hline MG-8 & $\mathrm{NaOH}=0 \mathrm{~mL}$ & Glass solid & No dispersion & \\
\hline MG-9 & $\mathrm{NaOH}=6 \mathrm{~mL}$ & $288 \pm 100$ & Reasonable dispersion & Irregular spherical particles \\
\hline MG-10 & $\mathrm{NaOH}=9 \mathrm{~mL}$ & $\begin{array}{l}\text { No spherical } \\
\text { particles }\end{array}$ & Poor dispersion & Cluster of amorphous materials \\
\hline MG-11 & $\mathrm{C}_{12} \mathrm{TMABr}=0 \mathrm{~g}$ & No product & No product & No product \\
\hline MG-12 & $\mathrm{C}_{12} \mathrm{TMABr}=0.84 \mathrm{~g}$ & $357 \pm 22$ & Reasonable dispersion & $\begin{array}{c}\text { Spherical particles, } \\
\text { some amorphous particles }\end{array}$ \\
\hline MG-13 & $\mathrm{C}_{12} \mathrm{TMABr}=3.36 \mathrm{~g}$ & $35 \pm 7$ & Poor dispersion & Cluster of spherical particles \\
\hline
\end{tabular}

${ }^{\star} \mathrm{mL}=$ milliliters, $\mathrm{g}=$ grams, Et-G = ethylene glycol.
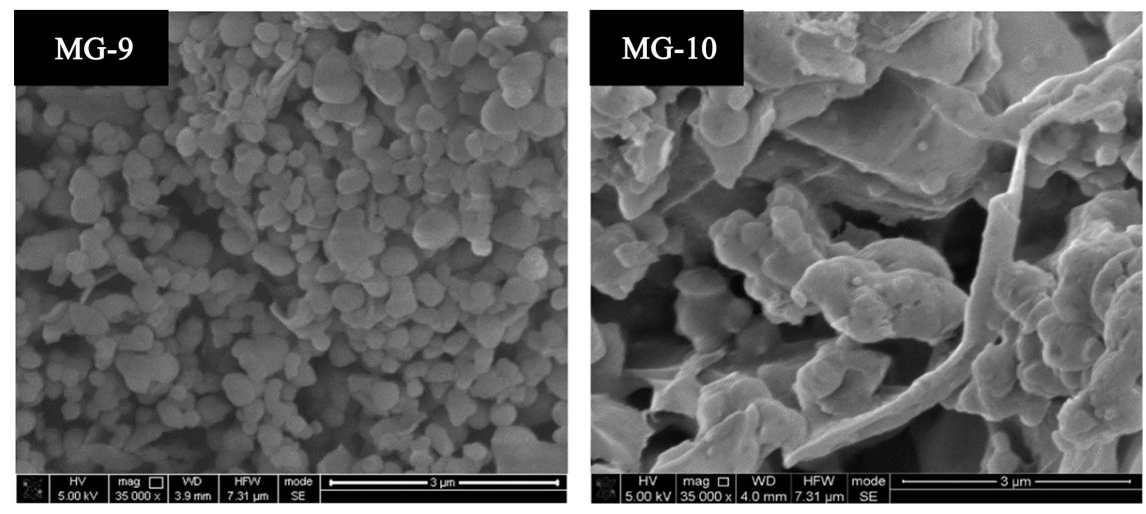

Figure 3. SEM Images of mesoporous silica particles (Batch MG-9 and 10).

size of particles. The study revealed that none of the material was obtained in the absence of a template "Batch MG-11" (Table 2). The size of the particles decreased with increasing the quantity of template $\left(\mathrm{C}_{12} \mathrm{TMABr}\right)$. On the other hand, the morphology of the particles enhanced at a low quantity of surfactant (Figure 1 and Figure 4). The smallest particles size $(35 \pm 7 \mathrm{~nm})$ in the current research was obtained when a large quantity of surfactant was used as in batch MG-13 (Table 2). 

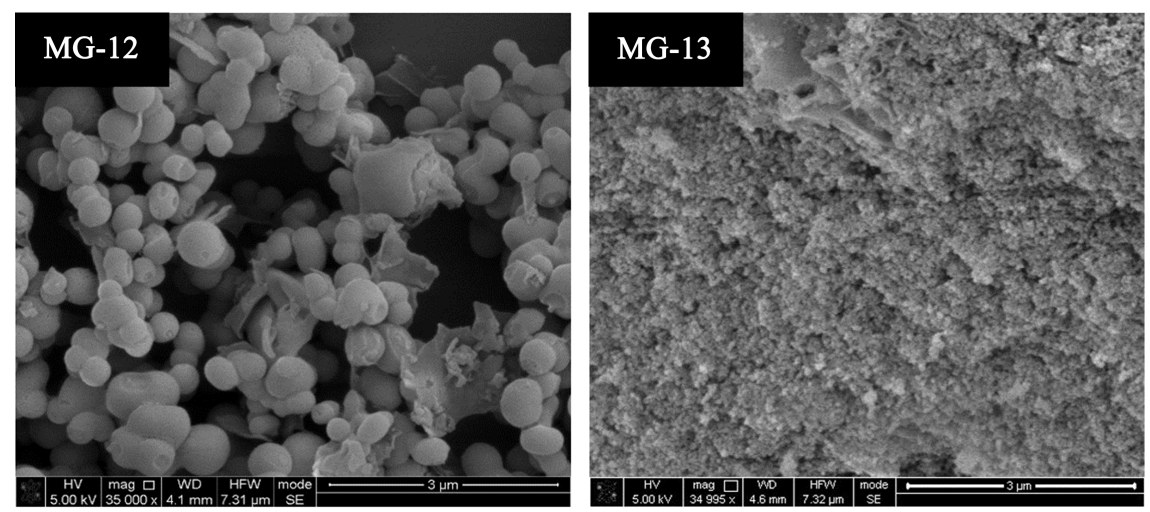

Figure 4. SEM Images of mesoporous silica particles (Batch MG-12 and 13).

\subsection{Surface Area and Pore Size Distribution}

The porosity of particles was studied and characterized by $\mathrm{N}_{2}$ adsorption isotherm. The BET method was used to calculate the surface area and pore size distribution [17]. The prepared silica particles in all batches showed an isotherm belonging to type IV which occur when the material is mesoporous [18]. The study revealed that alteration in the concentration of chemical reagents affects both surface area "350 $-1204 \mathrm{~m}^{2} \cdot \mathrm{g}^{-1}$ " and average pore radius " $1.62-4.5 \mathrm{~nm}$ " (Table 3). The surface area decreased with increasing the quantity of silica precursor in the reaction medium. Furthermore, a dramatic drop in the surface area "353.5137 $\mathrm{m}^{2} \cdot \mathrm{g}^{-1}$ " was noticed when the reaction run without deionized water due to the low solubility of the surfactant on ethylene glycol leading to low concentration of micelles. The relationship between the surface area and the amount of water used in the reaction is a direct relationship. However, there was no obvious effect of $\mathrm{pH}$ value on the surface area or pore size. A slight increase in the surface area with increasing the quantity of $\mathrm{C}_{12} \mathrm{TMABr}$ (Table 3 ).

\subsection{Template Removal}

Removal of surfactant from mesostructure is usually carried out using combustion or solvent extraction. The combustion is the easy way to remove the template as it is simple, green, and free solvent waste provided that the temperature does not exceed " $600^{\circ} \mathrm{C}$ ", and its increase may lead to the collapse of the mesostructure and destroy the particles. To prove the removal of template from the particles structure, the prepared particles in different batches were characterized by TGA and FT-IR before and after combustion. Thermogravimetric analyses carried out from " $30^{\circ} \mathrm{C}$ to $800^{\circ} \mathrm{C}$ " showed in general three regions of weight loss. The first change occurred between " $37^{\circ} \mathrm{C}$ and $180^{\circ} \mathrm{C}$ ", a weight loss thought to be that of water adsorbed on the silica surface and residual solvent and unreacted materials [19]. There was then a large weight loss from " $180^{\circ} \mathrm{C}$ to $350^{\circ} \mathrm{C}$ ", followed by a slight weight loss between " $350^{\circ} \mathrm{C}$ and $420^{\circ} \mathrm{C}$ ". Most of the weight was lost between " $180^{\circ} \mathrm{C}$ to $350^{\circ} \mathrm{C}$ " due to the burning off surfactant (Figure 5). No significant change was observed between " $420^{\circ} \mathrm{C}$ to $800^{\circ} \mathrm{C}$ " except for batch MG-10-b, this slight weight loss might be due to the nature of prepared 


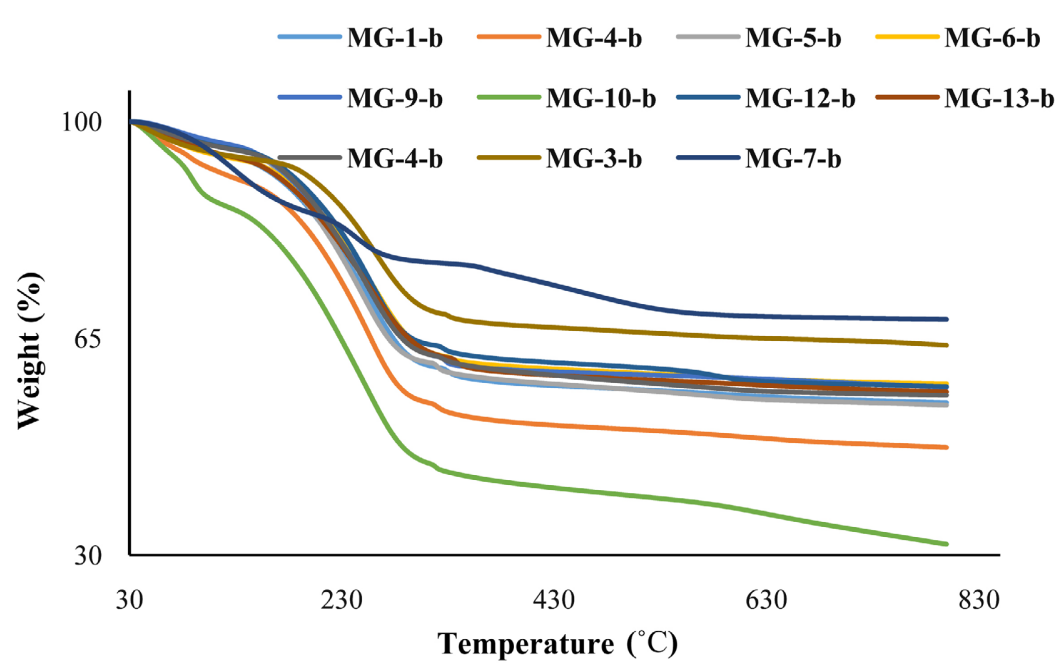

Figure 5. Thermogravimetric analysis of mesoporous silicas before burning off surfactant.

Table 3. Surface area and $\mathrm{BJH}$ pore radius of prepared mesoporous silicas.

\begin{tabular}{|c|c|c|c|}
\hline Batch & $\begin{array}{l}\text { Main Change on } \\
\text { the Reaction content }\end{array}$ & $\begin{array}{l}\text { BET Surface } \\
\text { area " } \mathrm{m}^{2} \cdot \mathrm{g}^{-1} "\end{array}$ & $\begin{array}{l}\text { BJH Desorption average } \\
\text { pore radius }(2 \mathrm{~V} / \mathrm{A}) \text { " } \mathrm{nm} \text { " }\end{array}$ \\
\hline MG-1 & $\mathrm{TMOS}=1.8 \mathrm{~mL}$ & 1048.3589 & 2.3868 \\
\hline MG-2 & $\mathrm{TMOS}=0.9 \mathrm{~mL}$ & 950.3557 & 2.7914 \\
\hline MG-3 & $\mathrm{TMOS}=3.6 \mathrm{~mL}$ & 786.7364 & 1.9964 \\
\hline MG-4 & DI-W: Et-G = (200:200) mL & 912.7860 & 2.5840 \\
\hline MG-5 & DI-W: Et-G = (90:310) mL & 1036.2929 & 4.4995 \\
\hline MG-6 & DI-W: Et-G = (400:0) & 1095.2449 & 1.6901 \\
\hline MG-7 & DI-W: Et-G $=(0: 400) \mathrm{mL}$ & 353.5137 & 1.9073 \\
\hline MG-9 & $\mathrm{NaOH}=6 \mathrm{~mL}$ & 1177.8755 & 1.8582 \\
\hline MG-10 & $\mathrm{NaOH}=9 \mathrm{~mL}$ & 1157.8085 & 1.6199 \\
\hline MG-12 & $\mathrm{C}_{12} \mathrm{TMABr}=0.84 \mathrm{~g}$ & 1013.4154 & 1.9900 \\
\hline MG-13 & $\mathrm{C}_{12} \mathrm{TMABr}=3.36 \mathrm{~g}$ & 1204.1273 & 3.0664 \\
\hline
\end{tabular}

${ }^{*} \mathrm{~mL}=$ milliliters, $\mathrm{g}=$ grams, Brunauer, Emmett $\&$ Teller $(\mathrm{BET})$.

amorphous materials. The large weight loss between " $180^{\circ} \mathrm{C}$ to $350^{\circ} \mathrm{C}$ " disappeared from TG trace after silica particles combustion approving complete surfactant removal from silica structure (Figure 6).

FT-IR spectroscopy was used for further approval of surfactant removal from silica mesostructure, FT-IR spectroscopy was carried out for prepared particles before and after combustion. The $\mathrm{CH}_{2}$ and $\mathrm{CH}_{3}$ stretching peaks at " 2925 and $2851 \mathrm{~cm}^{-1}$ " (Figure 7) disappeared from the IR spectra after burning off the or-

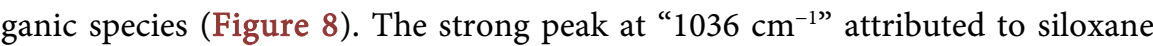
"Si-O-Si" group. The Si-O band was observed at " $791 \mathrm{~cm}^{-1}$ ". Some batches have a slight peak at "2925 and $2851 \mathrm{~cm}^{-1}$ " due to uncompleted removal of the surfactant from the mesoporous silica structure. 


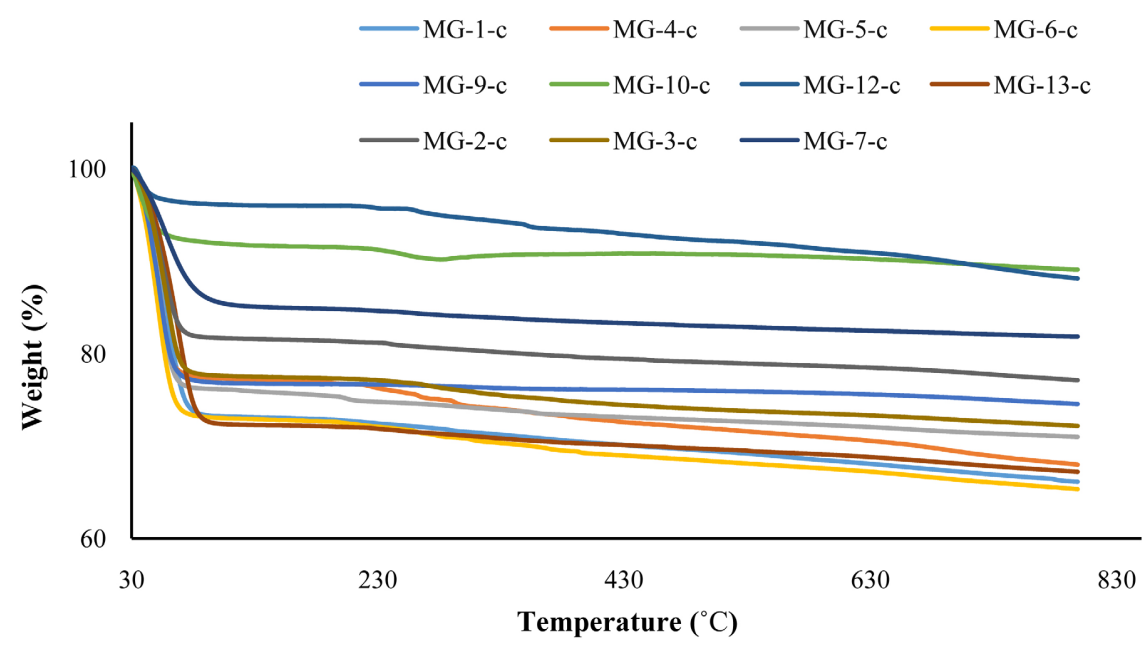

Figure 6. Thermogravimetric analysis of mesoporous silicas after burning off surfactant.

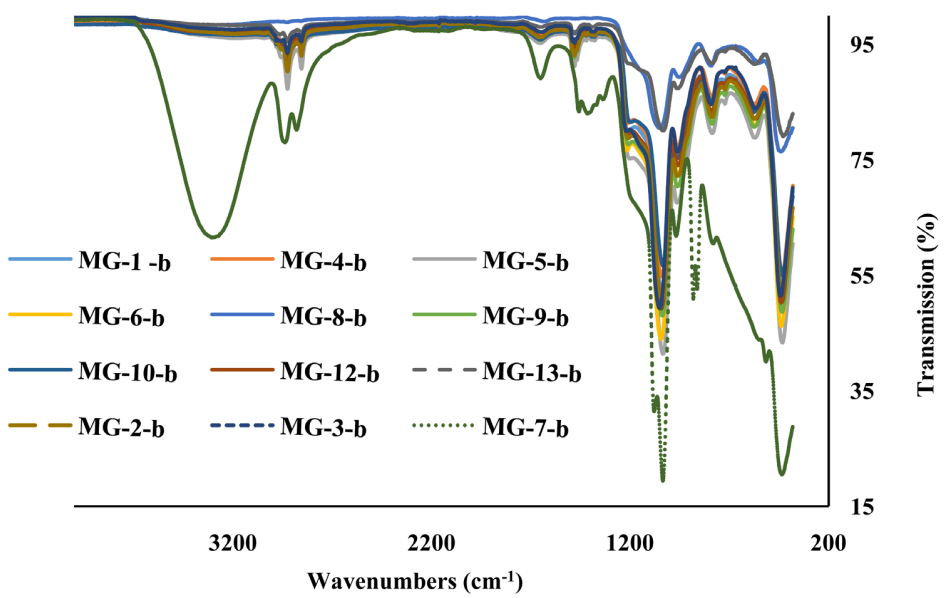

Figure 7. FT-IR spectroscopy of prepared mesoporous silicas before surfactant combustion.

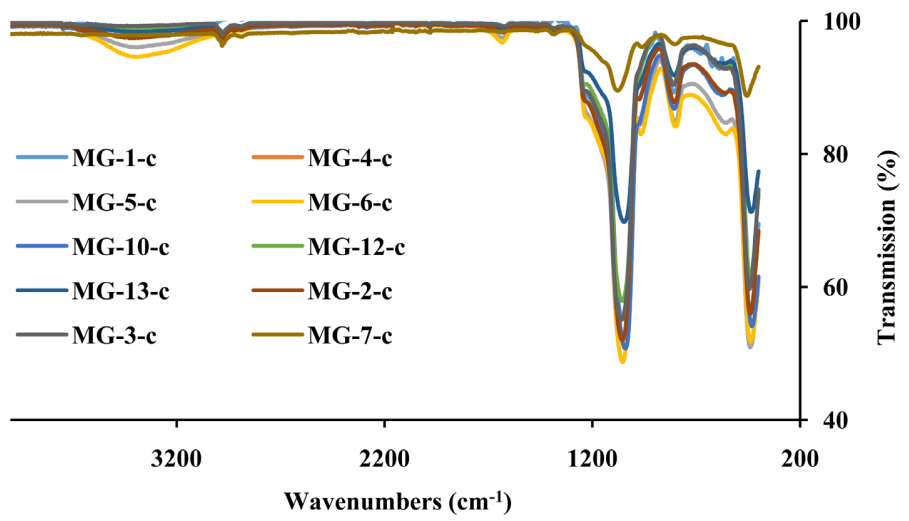

Figure 8. FT-IR spectroscopy of prepared mesoporous silicas after surfactant combustion.

\section{Conclusion}

The current study revealed that altering the concentration of reagents used to 
prepare mesoporous silica particles leads to changes in the physical characteristics of the particles like morphologies, sizes, and surface area. The study also confirms that these changes were obtained due to variations in the quantity of TMOS, the volume ratio of (DI-W: Et-G), $\mathrm{NaOH}$, and $\mathrm{C}_{12} \mathrm{TMABr}$. Therefore, it is very important to adjust these factors to control the size, morphology and surface area of the particles and get the desirable silica particles. As a result, mesoporous silicas with average sizes ranging from " 35 to $550 \mathrm{~nm}$ ", various morphology, average pore radius " $1.62-4.5 \mathrm{~nm}$ " and different surface area "350 $1204 \mathrm{~m}^{2} \cdot \mathrm{g}^{-1}$ " were prepared successfully by controlling the concentration of these factors during the preparation of silica particles. These prepared mesoporous silicas may be used as a substrate in various applications such as drug delivery and extraction of hazardous materials from water. Current work is the initial part of ongoing work as further experimentation is in continuation to study effect of type of solvent and surfactant on the silica particles characteristics.

\section{Acknowledgements}

The authors would like to acknowledge the support received from King Khalid Military Academy, Saudi Arabia, Durham University, UK, Dr Paul McGonigal, Dr. Leon Bowen and Dr. Budhika Mendis.

\section{Conflicts of Interest}

The author declares no conflicts of interest regarding the publication of this paper.

\section{References}

[1] Pagar, O.B., Nagare, H.S., Chine, Y.M., Autade, R.R., Narode, P.R. and Sanklecha, V.M. (2018) Mesoporous Silica: A Review. International Journal of Pharmaceutics and Drug Analysis, 6, 1-12.

[2] Ottone, C., Romero, O., Urrutia, P., Bernal, C., Illanes, A. and Wilson, L. (2021) Enzyme Biocatalysis and Sustainability. In: Piumetti, M. and Bensaid S., Eds., Nanostructured Catalysts for Environmental Applications, Springer, Cham, 383-413. https://doi.org/10.1007/978-3-030-58934-9 14

[3] Ferris, D.P., McGonigal, P.R., Witus, L.S., Kawaji, T., Algaradah, M.M., Alnajadah, A.R., Nassar, M.S. and Stoddart, J.F. (2015) Oxime Ligation on the Surface of Mesoporous Silica Nanoparticles. Organic Letters, 17, 2146-2149.

https://doi.org/10.1021/acs.orglett.5b00740

[4] Blanford, C.F., Yan, H., Schroden, R.C., Al-Daous, M. and Stein, A. (2001) Gems of Chemistry and Physics: Macroporous Metal Oxides with 3D Order. Advanced Materials, 13, 401-407. https://doi.org/10.1002/1521-4095(200103)13:6<401::AID-ADMA401>3.0.CO;2-7

[5] Algaradah, M. (2021) A Mercapto Based Nanoscavenger as Promising Tool for the Dispersion Preconcentration of Trace Elements in Contaminated Waters. Egyptian Journal of Chemistry, In Press. https://doi.org/10.21608/ejchem.2021.66064.3429

[6] Liudmyla Karachevtseva, M.K., Wang, B., Lytvynenko, O. and Sementsov, Y. (2019) Nanocoatings on 2D Macroporous Silicon Structures. Journal of Materials Science and Chemical Engineering, 7, 12-20. https://doi.org/10.4236/msce.2019.77002 
[7] Duan, Y., Zhao, X., Sun, M. and Hao, H. (2021) Research Advances in the Synthesis, Application, Assembly, and Calculation of Janus Materials. Industrial \& Engineering Chemistry Research, 60, 1071-1095. https://doi.org/10.1021/acs.iecr.0c04304

[8] Kobryń, J., Dałek, J. and Musiał, W. (2021) The Influence of Selected Factors on the Aqueous Cryptotanshinone Solubility. Pharmaceutics, 13, Article No. 992. https://doi.org/10.3390/pharmaceutics13070992

[9] Issa, A.A. and Luyt, A.S. (2019) Kinetics of Alkoxysilanes and Organoalkoxysilanes Polymerization: A Review. Polymers, 11, Article No. 537. https://doi.org/10.3390/polym11030537

[10] El Seoud, O.A., Keppeler, N., Malek, N.I. and Galgano, P.D. (2021) Ionic LiquidBased Surfactants: Recent Advances in Their Syntheses, Solution Properties, and Applications. Polymers, 13, Article No. 1100. https://doi.org/10.3390/polym13071100

[11] Narayan, R., Nayak, U.Y., Raichur, A.M. and Garg, S. (2018) Mesoporous Silica Nanoparticles: A Comprehensive Review on Synthesis and Recent Advances. Pharmaceutics, 10, Article No. 118. https://doi.org/10.3390/pharmaceutics10030118

[12] Hara, T., Makino, S., Watanabe, Y., Ikegami, T., Cabrera, K., Smarsly, B. and Tanaka, N. (2010) The Performance of Hybrid Monolithic Silica Capillary Columns Prepared by Changing Feed Ratios of Tetramethoxysilane and Methyltrimethoxysilane. Journal of Chromatography A, 1217, 89-98.

https://doi.org/10.1016/j.chroma.2009.11.019

[13] Cadrazco, M., Santamaría, A., Jaramillo, I.C., Kaur, K., Kelly, K.E. and Agudelo, J.R. (2020) Characterization of Renewable Diesel Particulate Matter Gathered from NonPremixed and Partially Premixed Flame Burners and from a Diesel Engine. Combustion and Flame, 214, 65-79. https://doi.org/10.1016/j.combustflame.2019.12.018

[14] Zarrintaj, P., Ramsey, J.D., Samadi, A., Atoufi, Z., Yazdi, M.K., Ganjali, M.R., Amirabad, L.M., Zangene, E., Farokhi, M., Formela, K., Saeb, M.R., Mozafari, M. and Thomas, S. (2020) Poloxamer: A Versatile Tri-Block Copolymer for Biomedical Applications. Acta Biomaterialia, 110, 37-67.

https://doi.org/10.1016/j.actbio.2020.04.028

[15] Lin, H.P. and Tsai, C.P. (2003) Synthesis of Mesoporous Silica Nanoparticles from a Low-Concentration $\mathrm{C}_{\mathrm{n}} \mathrm{TMAX}$-Sodium Silicate Components. Chemistry Letters, 32, 1092-1093. https://doi.org/10.1246/cl.2003.1092

[16] Yano, K. and Fukushima, Y. (2004) Synthesis of Mono-Dispersed Mesoporous Silica Spheres with Highly Ordered Hexagonal Regularity Using Conventional Alkyltrimethylammonium Halide as a Surfactant. Journal of Materials Chemistry, 14, 1579-1584. https://doi.org/10.1039/b313712k

[17] Brunnauer, S., Emmett, P.H. and Teller, E. (1938) Adsorption of Gases in Multimolecular Layers. Journal of the American Chemical Society, 60, 309-319.

https://doi.org/10.1021/ja01269a023

[18] Balbuena, P.B. and Gubbins, K.E. (1993) Theoretical Interpretation of Adsorption Behavior of Simple Fluids in Slit Pores. Langmuir, 9, 1801-1814.

https://doi.org/10.1021/la00031a031

[19] Ui, S.W., Lim, S.J., Lee, S.H. and Choi, S.C. (2009) Control of the Size and Morphology of Nano-Size Silica Particles Using a Sodium Silicate Solution. Journal of Ceramic Processing Research, 10, 553-558. 